\title{
A Educação Ambiental na Escola Estadual Anízio Rodrigues Coelho, à partir do Projeto "Qualidade de Vida e Ações Sustentáveis"
}

\author{
Eva Lopes de Macedo Cordeiro ${ }^{1}$; Márcia Cristina Moraes Cotas Videira ${ }^{2}$
}

\begin{abstract}
Resumo: Este artigo discute acerca de um projeto de educação ambiental na Escola Estadual Anízio Rodrigues Coelho, intitulado "Qualidade de vida e ações sustentáveis". Trata-se de uma pesquisa qualitativa participativa, tendo como sujeitos uma coordenadora pedagógica, alunos e professores do nono ano da escola citada. Foram desenvolvidas ações voltadas principalmente ao pleno uso dos recursos hídricos na escola e nas residências da comunidade escolar. Os dados coletados vieram de análise documental (Projeto); observação participantes e entrevistas - sem guias estruturadas; registros fotográficos. Os resultados demonstraram ganhos educacionais que ultrapassam os muros da escola por meio do desenvolvimento do Projeto, que produziu como resultado uma mudança de comportamento da comunidade escolar, por meio da prática de ações sustentáveis na escola e nas residências. Recomenda-se que o estudo sirva de referência para a implementação de outros projetos congêneres em outras instituições visando práticas e transformações necessárias ao desenvolvimento local sustentável do distrito de Nascente.
\end{abstract}

Palavras chave: Educação Ambiental, Projeto, Ações sustentáveis.

\section{Environmental Education in the State School Anízio Rodrigues Coelho from the Project "Quality of Life and Sustainable Actions"}

\begin{abstract}
This article discusses an environmental education project at the Anízio Rodrigues Coelho State School, entitled "Quality of life and sustainable actions". It is a participatory qualitative research, having as subjects a pedagogical coordinator, students and teachers of the ninth year of the mentioned school. Actions have been developed mainly aimed at the full use of water resources in school and in the residences of the school community. The data collected came from documentary analysis (Project); observation participants and interviews - no structured guides; photographic records. The results demonstrated educational gains that went beyond school walls through the development of the Project, which resulted in a change in the behavior of the school community through the practice of sustainable actions at school and in homes. It is recommended that the study serve as a reference for the implementation of other similar projects in other institutions aiming at practices and transformations necessary for the local sustainable development of Nascente district.
\end{abstract}

Keywords: Environmental Education, Project, Sustainable actions.

\footnotetext{
${ }^{1}$ Doutorado em Ciências da Educação - Universsidad Hispano Guaraní. Educadora de Apoio e Articuladora do Projeto Novo Mais Educação na Escola Anízio Rodrigues Coelho. Professora na Escola Municipal Eva Modesto Cordeiro;

${ }^{2}$ Doutora em Ciencias de la Educación pela Universidad Autónoma de Asunción - Py. Mestre em Ciencias de la Educación pela Universidade Autónoma de Asunción - Py. Especialista em Matemática para a Educação Básica pela UFMT/CUR. Especialista em Gestão Escolar e Didática no Ensino Superior pela Faculdade João Calvino - BA. Professora em especializações da Faculdade João Calvino - BA. Professora de Metodologia de pesquisa Científica, Avaliação de Programas e Projetos Institucionais, Gestão e Administração em Entidades Educativas no Mestrado em Ciências da Educação na UTIC - PY.
} 


\section{Introdução}

No decorrer da vida escolar, durante todo o aprendizado, o aluno estuda diversas disciplinas, pelas quais engloba o meio ambiente. Apesar disso cabe questionar porque ainda se passa por tantos problemas ambientais, principalmente quando na educação escolar e em toda a mídia se fala da importância do meio ambiente desde os primórdios do aprendizado formal?

A educação ambiental, prevista na Constituição Federal brasileira, deve ser inserida em todos os níveis de ensino, para que os alunos futuramente sejam pessoas conscientes da importância de um meio ambiente ecologicamente equilibrado. Tendo essa preocupação com o meio ambiente é que se acredita que a educação ambiental é a única estratégia para uma mudança efetiva na preservação da espécie humana, vivendo com considerável qualidade de vida.

A educação ambiental deve capacitar ao pleno exercício da cidadania permitindo a formação de uma base conceitual suficientemente diversificada técnica e culturalmente de modo a permitir que sejam superados os obstáculos à utilização sustentável do meio. Para que isso ocorra, é preciso formar pessoas conscientes, críticas, éticas, preparadas para enfrentar esse novo paradigma.

À partir dos anos 1980, ampliou-se o uso de instrumentos de controle como taxas, encargos, permissões de mercado, sendo o principal objetivo dos instrumentos de mercado provocar mudanças de comportamento pela punição em termos monetários e a taxação ambiental, provendo-se incentivos para melhoria da perfomance ambiental dos empreendimentos.

A aprovação da Lei $n^{\circ}$ 9.795, de 27.4.1999 e do seu regulamento, o Decreto ${ }^{\circ} 4.281$, de 25.6.2002, estabelecendo a Política Nacional de Educação Ambiental (PNEA), trouxe grande esperança, especialmente para os educadores, ambientalistas e professores, pois há muito já se fazia educação ambiental, independente de haver ou não um marco legal (LIPAI, LAYLARGUES E PEDRO, apud MELLO E TRAJBER, 2007, p. 24).

Necessário se faz a realização de políticas públicas urgentes voltadas para o meio ambiente, e uma conscientização maciça da população em geral alertando para os riscos de ações antrópicas indiscriminadas a fim de que se evite entregar para as gerações futuras um ambiente em total estado de decomposição. 


\section{Educação Ambiental nas escolas}

De acordo Rodrigues e Rodrigues (2001), o tema transversal Meio Ambiente sugere a abordagem da EA em todos os ciclos da educação fundamental. Independente da área de ensino, a EA deve ser promovida ao longo de eixos temáticos que norteiam esse tema transversal. Assim, percebe-se a importância da inclusão do Meio Ambiente nos currículos escolares, permeando toda prática educacional.

Segundo Vasconcellos (1997) a presença, em todas as práticas educativas, da reflexão sobre as relações dos seres entre si, do ser humano com ele mesmo e do ser humano com seus semelhantes é condição imprescindível para que a EA ocorra. Dentro desse contexto, conforme expõe Dias (2000), sobressem-se as escolas, como espaços privilegiados na implementação de atividades que propiciem essa reflexão, pois isso necessita de atividades de sala de aula e atividades de campo, com ações orientadas em projetos e em processos de participação que levem à autoconfiança, às atitudes positivas e ao comprometimento pessoal com a proteção ambiental implementados de modo interdisciplinar.

A educação ambiental deve ser entendida como educação política, no sentido de que ela reivindica e prepara os cidadãos para exigir justiça social, cidadania nacional e planetária, autogestão e ética nas relações sociais e com a natureza (AGENDA 21, 1996, apud MPF, s/d).

Considerando a importância da temática ambiental e a visão integrada do mundo, no tempo e no espaço, sobressem-se as escolas, como espaços privilegiados na implementação de atividades que propiciem essa reflexão, pois isso, segundo Dias (2000), necessita de atividades de sala de aula e atividades de campo, com ações orientadas em projetos e em processos de participação que levem à autoconfiança, a atitudes positivas e ao comprometimento pessoal com a proteção ambiental implementados de modo interdisciplinar.

A escola dentro da EA deve sensibilizar o aluno a buscar valores que conduzam a uma convivência harmoniosa com o ambiente e as demais espécies que habitam o planeta, auxiliando-o a analisar criticamente os princípios que tem levado à destruição inconseqüente dos recursos naturais e de várias espécies. Tendo a clareza que a natureza não é fonte inesgotável de recursos, suas reservas são finitas e devem ser utilizadas de maneira racional, evitando o desperdício e considerando a reciclagem como processo vital. E as demais espécies que existem no planeta merecem nosso respeito. Além disso, a manutenção da biodiversidade é fundamental para a sobrevivência humana.

A educação ambiental se torna um exercício para a cidadania. Ela tem como objetivo a conscientização das pessoas em relação ao mundo em que vivem para que possam ter cada vez mais qualidade de vida sem desrespeitar o meio ambiente natural que a cercam. Essa conscientização se dá a partir do conhecimento de seus recursos, os aspectos da fauna e da flora gerais e, específicos de cada região; e, os problemas ambientais causados pela exploração do homem, assim como os aspectos 
culturais que vão se modificando com o passar do tempo e da mudança dos recursos naturais, como a extinção de algumas espécies por exemplo.

O maior objetivo é tentar criar uma nova mentalidade com relação a como usufruir dos recursos oferecidos pela natureza, criando assim um novo modelo de comportamento. A educação ambiental é um exercício para a participação comunitária e não individualista. Implementar a Educação Ambiental nas escolas tem se mostrado uma tarefa exaustiva. Existem grandes dificuldades nas atividades de sensibilização e formação, na implantação de atividades e projetos e, principalmente manutenção e continuidade dos já existentes.

Para Pelicioni (2000) a educação ambiental deve, portanto, capacitar ao pleno exercício da cidadania permitindo a formação de uma base conceitual suficientemente diversificada técnica e culturalmente de modo a permitir que sejam superados os obstáculos à utilização sustentável do meio. Para que isso ocorra, é preciso formar pessoas conscientes, críticas, éticas, preparadas, portanto, para enfrentar esse novo paradigma. As principais finalidades da EA são:

\footnotetext{
Ajudar a fazer e compreender claramente, a existência da interdependência econômica, social, política e ecológica, nas zonas urbanas e rurais;

Proporcionar, a todas as pessoas, a possibilidade de adquirir os conhecimentos, o sentido dos valores, as atitudes, o interesse ativo a as atitudes, necessárias para proteger e melhorar o meio ambiente; Induzir novas formas de conduta nos indivíduos, nos grupos sociais e na sociedade em seu conjunto, a respeito do meio ambiente (PELICIONI, 2000, p. 02).
}

A educação ambiental nos níveis formais e informais tem procurado desempenhar esse difícil papel resgatando valores como o respeito à vida e à natureza, entre outros, de forma a tornar a sociedade mais justa e feliz. Na opinião de Pelicioni (2000), os professores precisam entender que a abrangência da Educação Ambiental, cujo enfoque em qualidade de vida, torna os tópicos Doenças Sexualmente Transmissíveis e Planejamento Familiar - diretamente relacionados. Questões de Ética, Pluralidade Cultural, Meio Ambiente, Saúde e Orientação Sexual também entram no mérito da EA.

\section{A prática da educação ambiental orientada pelo professor}

A aprendizagem centrada (contextualizada) é integrada à preocupação em retirar o aluno da condição de espectador passivo, em produzir uma aprendizagem significativa e em desenvolver o conhecimento espontâneo em direção ao conhecimento abstrato. Nesse sentido, considera a estratégia de desenvolver projeto, uma metodologia capaz de contribuir com esse novo atendimento em relação ao aluno como agente construtor do próprio conhecimento. 
Os PCNs (BRASIL, 1997) reforçam que o aluno deve ser estimulado a questionar a sua própria resposta, a questionar o problema, a transformar um dado problema numa fonte de novos problemas, a formular problemas a partir de determinadas informações, a analisar problemas abertos que admitem diferentes respostas em função de certas condições. Essa prática nem sempre é considerada, no entanto, entende-se que, no contexto desse estudo, que trabalhar com projeto a partir da prática é peça chave no envolvimento ativo do aluno como parte integrante no processo de aprendizagem. $\mathrm{O}$ aluno é instigado a pesquisar, a problematizar, a buscar recursos que possam de fato construir o próprio conhecimento.

Oliva et. al. (2004) apresenta resumidamente as pretensões que têm orientado experiências como o ensino através de projetos e investigações, como segue.

1. Implicar al alimnado em el proceso de enseñanza-aprendizage fomentando actitudes positivas havia la ciência y su aprendizage.

2. contribuir al desarrollo de la creatividad y de actitudes y procedimientos científicos asociados a este tipo de actividad.

3. Crear una actitud de colaboración, participación y responsabilidad en el alumnado.

4. Proporcionar un entorno en el que se desenrrolle favorablemente el clima de relaciones humanas.

5. Hacer protagonistas a los alumnos y mejorar su autoestima, a través de una experiencia repleta de obstáculos y dificultades, pero que al final pudiera aportar la satisfación de ver reconocido su trabajo. 6. La posibilidad de transferir ese clima de trabajo y las habilidades adquiridas al aprendizaje formal de las aulas (OLIVA et. al., 2004, p. 429).

Todas essas considerações dos autores certamente permeiam o desenvolvimento de uma estratégia de ensino e aprendizagem que levem o aluno à construção do próprio conhecimento, valorizando seus préconhecimentos, transformando estes em novos conhecimentos, que possam ao máximo, ser aplicados no cotidiano do aluno. Na opinião de Henriques et. al. (2007, p. 23) "a riqueza de experiências e a criatividade na construção das práticas demonstram a vitalidade do que ocorre na escola.".

A EA é um processo visa formar uma população mais consciente e preocupada com o ambiente e com os problemas que lhe dizem respeito, com conhecimentos, competências, o estado de espírito, as motivações e o sentido de participação e engajamento que the permita trabalhar individual e coletivamente para resolver os problemas atuais e impedir que se repitam. Conforme o artigo $10^{\circ}$ da Política Nacional de Educação Ambiental, a EA deve ser desenvolvida como uma prática educativa integrada, contínua e permanente em todos os níveis e modalidades do ensino formal.

Um bom exemplo são as aulas de EA em zoológicos, parques, praças, ruas do bairro onde a escola está inserida e até no próprio pátio da escola, onde as explicações, juntamente com o contato com os recursos naturais, são de extrema importância no processo de conscientização ambiental. A coleta seletiva do lixo, a redução no desperdício de água, entre outras atitudes que contribuem com o meio 
ambiente, são ações que devem ser solicitadas, tanto na escola como nas casas dos alunos, proporcionando que eles sejam agentes participativos do processo de ensino aprendizagem e, principalmente, visualizando o resultado e havendo uma mudança comportamental.

\begin{abstract}
Atividades extracurriculares, como visitas a depósitos de reciclagem, plantio de árvores e ações comunitárias, ajudam a desenvolver a cidadania das crianças. E sempre que for introduzido um novo assunto na educação escolar é preciso que se faça uma pesquisa sobre os recursos, a qualidade e a metodologia que serão utilizados na abordagem do tema, pois, desse modo, o aluno aprende de forma clara e precisa (ABREU, 2011).
\end{abstract}

Segundo Pasquali et. all. (2006), muitos professores se interessam em adotar aulas alternativas, mas encontram desafios, como a falta de recrusos financeiros ou falta de apoio para desenvolver projetos de educação ambiental. São problemas que geralmente ocorrem em escola públicas estaduais e municipais, o que dificulta muitas vezes a aplicação de qualquer atividade que extrapole o quadro negro e o giz.

Uma alternativa para a inclusão da temática ambiental no meio escolar é a aprendizagem em forma de projetos. Segundo Capra (2003), essa é uma proposta alinhada ao entendimento do processo de aprendizagem que sugere a necessidade de estratégias de ensino mais adequadas evidenciando a importância de um currículo integrado que valorize o conhecimento contextual, no qual as várias disciplinas sejam vistas como recursos a serviço de um objeto central.

Além disso, Nalini (2003) argumenta que as atividades de educação ambiental precisam extrapolar o âmbito escolar e promover o aprendizado e, até, a transformação de todos nós. A tarefa de proteger a natureza precisa permanente. Na maioria dos temas transversais, educação ambiental é um muito abrangente e a maioria dos projetos que se propõem a trabalhar o assunto procuram concentrarse em focos mais específicos dentro deste grande assunto.

Assim, a educação é voltada para a conscientização ambiental, proporcionando um processo de alfabetização ecológica, podendo ser abordada de diferentes formas na sala de aula. O professor deve utilizar metodologias criativas para obter a atenção e participação de todos os alunos, promovendo a conscientização ambiental.

O portal Rizomas (2008) disponibiliza um banco de dados com diversos tipos de recursos didáticos, como vídeos, textos, aulas práticas, experimentos, que podem ser utilizados livremente, são públicos. Aléms disso disponibiliza matérias para e por disciplina, com: animação/simulação, imagem, áudio, mapa, experimento prático, software educacional, hipertexto, vídeo. A forma de trabalhar depende de cada professor. Em anexo, uma Atividade/experimento muito interessante, destacado dentre os tantos disponíveis do portal Rizomas.

Pensando em melhorar essa situação surgiu a ideia do consumo consciente, que é aquele que busca atender as necessidades humanas escolhendo produtos ou procedimentos que diminuam os 
impactos negativos e aumentem os impactos positivos ao meio ambiente e a sociedade. Essa é a proposta do desenvolvimento sustentável, harmonizar o desenvolvimento social e a conservação ambiental.

Exemplos de Práticas de Consumo Consciente, segundo o Ministério Público Federal (s/d), são as ações para redução do consumo de água e energia e para utilização racional dos materiais de expediente; as aquisições de materiais e equipamentos mais eficientes e de produtos que causem menos impactos ao meio ambiente em seu processo de fabricação.

Os impactos ambientais passam a atingir todas as pessoas, sem distinção de cunho econômico, social ou cultural. Não há mais refúgio seguro. Todos finalmente passam a ter plena consciência do óbvio: a Terra é finita e a tecnologia não pode resolver todos os seus problemas. A água pode ser contaminada de muitas maneiras:

\begin{abstract}
Pela acumulação de lixos e detritos junto de fontes, poços e cursos de água; pelos esgotos domésticos que aldeias, vilas e cidades lançam nos rios ou nos mares; pelos resíduos tóxicos que algumas fábricas/indústrias lançam nos rios; pelos produtos químicos que os agricultores utilizam para combater as doenças das suas plantas, e que as águas das chuvas arrastam para os rios e para os lençóis de água existentes no subsolo; pela lavagem clandestina, ou seja, não autorizada, de barcos no alto mar, que largam combustíveis; pelos resíduos nucleares radioativos, depositados no fundo do mar; pelos naufrágios e acidentes que causam o derrame de milhares de toneladas de petróleo, sujando as águas e a costa e matam toda a vida marinha - as chamadas marés negras (FELIZARDO et. al., 2009, p. 13).
\end{abstract}

Faria (2009) afirma que o tratamento de água consiste na remoção de impurezas e contaminantes antes de destiná-la ao consumo. Entretanto, e infelizmente, mais de 1 bilhão de pessoas não têm acesso à água potável no mundo, seja por morarem em regiões secas ou por causa da poluição, ocasionando a morte de cerca de 1,8 milhões de crianças no mundo todo por causa de doenças como a diarréia, provocadas pelo consumo de água contaminada e más condições de saneamento.

Em condições de cobertura vegetal natural não perturbada, a taxa de infiltração é normalmente mantida no seu máximo. Em áreas compactadas, seja pelo preparo excessivo do solo, uso de máquinas pesadas, pé de arado, ou mesmo pelo pisoteio de animais, a infiltração é bem menor que em áreas florestais adjacentes. Segundo a AMBICENTER (2001), a infiltração da água no solo é bem maior em povoamentos florestais mais densos do que naqueles de menor densidade e ainda maior em povoamentos mais velhos.

Dos vários fatores que contribuem para a degradação das nascentes, destacam-se: desmatamento, erosão dos solos causada por práticas agressivas de uso da terra, atividades agropecuárias, reflorestamentos mal manejados e contaminação dos mananciais, conforme afirma Pinto (2003). Ve-se, portanto que, a ação humana é o principal fator de perturbação das nascentes, o que faz com que a sensibilização e participação das populações rurais a respeito de sua preservação sejam essenciais. 


\section{Práticas sustentáveis nas escolas}

O princípio da sustentabilidade aplica-se a um único empreendimento, a uma pequena comunidade até o planeta inteiro. Abreu (2010) argumenta que quando qualquer tema é abordado na educação escolar, faz-se necessária uma pesquisa para saber como está sendo trabalhado, qual a qualidade e os recursos utilizados para que os alunos o compreendam verdadeiramente. Nadal e Lopes (2010) explicam que uma escola pode praticar a sustentatbilidade a partir da construção conjunta de valores e atitudes:

Salas de aula com iluminação natural, painéis para a captação de energia solar, sistemas para a reutilização de água da chuva, área verde abundante. Essas características não são suficientes para uma escola promover o respeito à natureza. Para chegar lá, é fundamental que alunos, funcionários e até mesmo a comunidade do entorno tenham oportunidades diárias de construir novos valores e atitudes (NADAL; LOPES, 2010, p. 01)

As escolas de um modo geral trazem em seu currículo o tema ecologia, mas cada uma diferencia na maneira e qualidade de exposição do assunto. Há escolas que se tornam modelos a serem seguidos por seus exemplos diários de práticas sustentáveis e levam os alunos a participarem ativamente desse processo no ambiente escolar, em casa e na sociedade.

Nadal e Lopes (2010) argumentam que ser "ecologicamente sustentável” significa adotar uma postura de desenvolvimento que não prejudique o planeta no presente e satisfaça às reais necessidades humanas das próximas gerações. Isso, segundo as autoras, se enquadra em outro conceito, o de permacultura, criado em 1970.

O trabalho com o tema da sustetabilidade, para Abreu (2010) pode acontecer através de palestras, debates, gincanas além de atividades mais tradicionais, como trabalhos individuais e/ou em grupo, desenvolvimento de projetos sobre reciclagem, alimentação, economia do lar e outras temáticas voltadas ao meio ambiente. E nas escolas onde os temas são trabalhados, não se pode admitir, por exemplo: papéis, chicletes e restos de lanches espalhados pelo chão; carteiras com desenhos e rabiscos, pois assim, o trabalho não faz sentido em relação a tudo que os alunos aprenderam e pregaram.

Foi possível notar escolas que não dão maior importância ao fato, pois continuam deixando suas luzes acesas sem necessidade, as torneiras pingando, utilizando fortes produtos de limpeza e os alunos agindo como antes tanto na escola quanto fora dela.

Aplicar ações sustentáveis na escola significa tocar no assunto cotidianamente, não somente em datas comemorativas. Ação sustentável significa adotar estilos de vida que acentuem a qualidade de vida e subsistência material. 
Nadal (2010) expõe que, quando o assunto é trabalhar meio ambiente e fazer da escola um espaço sustentável, é comum achar que isso implica em reformas na estrutura física do prédio e altos investimentos. Não é bem assim. O fundamental é permitir que os alunos incorporem ao cotidiano atitudes voltadas à preservação dos recursos naturais.

$\mathrm{Na}$ escola, pode-se trabalhar a sustentabilidade pondo em prática, ações simples, como não desperdiçar água, cultivar áreas verdes e preferir produtos recicláveis. Assim, em pequena escala, tais procedimentos, ainda que não revertam os danos causados ao meio ambiente, têm grande impacto na rotina escolar.

Segundo Nadal (2010, p. 01) "a consciência de que as iniciativas da escola são fundamentais para promover a conscientização dos alunos, os futuros adultos que tomarão conta do planeta.". No desenvolvimento de projeto(s) da EA, é possível que os alunos aprendam a tomar decisões sustentáveis, no processo de ecoalfabetização. "A sustentabilidade se apoia no cuidado com as pessoas, a Terra e os recursos naturais" (p. 02).

A supracitada autora argumenta que o início do processo (prática de ações sustentáveis), pode ser iniciado pelos gestores, envolvendo funcionários e famílias do entorno. “As faxineiras, por exemplo, devem atentar ao descarte de lixo e produtos de limpeza e ao bom uso de água e energia. Já aos professores fica a tarefa de discutir as várias questões ambientais com os conteúdos das disciplinas.", exemplifica Nadal (2010, p. 02).

Os dados se apresentam aos sentidos e esses são revelados pelos sujeitos, conforme explica Minayo (2007).

Mesmo com a variedade de ferramentas, para proceder à coleta de informações cada qual guarda em si particularidades. A entrevista, a observação, o grupo focal, a história de vida ou a história oral, a sociometria, a pesquisa participante, entre outras, são formas de aproximar o pesquisador do fenômeno a ser investigado e igualmente de construir o conhecimento acerca desse fenômeno.

Realizou-se: a análise de documento (Projeto Qualidade de vida, ações sustentáveis); observação participante sem guia estruturada, entrevista livre (não estruturada, sem guia); registros fotográficos fornecidos pela escola. Nessa experiência de Pesquisa Participante as entrevistas formais serão encaradas como "conversas", como forma de aproximar ainda mais os interlocutores (professores e alunos do $9^{\circ}$ ano).

Os resultados da pesquisa qualitativa podem ser apresentados em forma de texto, e, na análise reunem-se os dados verbais e/ou audiovisuiais para determinar e descrever o fenômeno. 


\section{Desenvolvimento do Projeto}

O PPP da ecola investigada trata, dentre as atividades anuais obrigatórias, de desenvolver práticas e ações que contemplem a educação ambiental e o desenvolvimento sustentável. Mediante essa proposta, desenvolveu o Projeto "Qualidade de vida, ações sustentáveis" visando articular a comunidade escolar para o respeito e preservação do meio ambiente, estimulando a prática de ações sustentáveis, em benefício próprio e coletivo, tendo como principal foco, os recursos hídricos disponíveis na escola e nas residências da comunidade escolar.

De acordo com Machado (2000), é necessário compreender que no trabalho por projetos, as pessoas se envolvem para descobrir ou produzir algo novo, procurando respostas para questões ou problemas reais. "Não se faz projeto quando se têm certezas, ou quando se está imobilizado por dúvidas" (p. 7). O projeto parte inicialmente de uma problemática, quando se conhece, a priori, todos os passos para solucionar o problema. Para Almeida (2002), esse processo se constitui num exercício e aplicação do que já se sabe. Projeto não é com um conjunto de atividades propostas pelo professor para que os alunos realizem a partir de um tema dado, resultando numa apresentação de trabalho.

Na segunda etapa foram realizadas ações pedagógicas do projeto na escola, nos bairros e residências dos alunos e professores (de nono ano). Nas ações foi considerado o PPP com a inclusão de assuntos relacionados ao tema, envolvendo a interdisciplinaridade e a atuação das disciplinas e seus professores simultaneamente. As atividades foram programadas e desenvolvidas sob a perspectiva interdisciplinar para que se desenvolvesse o senso da perpcepção crítica dos fenômenos que ocorrem na escola, em seu entrono e nas comunidades onde professores e alunos residem, visando à conscientização de todos quanto à importância de praticar ações sustentáveis em relação à agua (recursos hídricos) onde trabalham / estudam e moram, e, consequentemente, melhorar a qualidade de vida.

[...] o projeto rompe com as fronteiras disciplinares, tornando-as permeáveis na ação de articular diferentes áreas de conhecimento, mobilizadas na investigação de problemáticas e situações da realidade. Isso não significa abandonar as disciplinas, mas integrá-las no desenvolvimento das investigações, aprofundadas verticalmente em sua própria identidade, ao mesmo tempo, que estabelecem articulações horizontais numa relação de reciprocidade entre elas, a qual tem como pano de fundo a unicidade do conhecimento em construção (ALMEIDA, 2002, p. 58).

Partindo do tema proposto, professores e alunos abordaram os conteúdos presentes das Diretrizes Curriculares Nacionais acerca dos Temas Transversais, em específico, Meio Ambiente (Educação Ambiental). Também, publicações sobre: abastecimento e distribuição de água, saneamento básico, uso/manejo de recursos hídricos, projetos escolares sobre Meio Ambiente e uso correto da água na escola e em casa - experiências que deram certo, e outros. Professores e alunos do nono ano 
participaram das atividades, recebendo subsídios para trabalhar, explanar e praticar, dentro de um processo holístico, desenvolvendo a percepção crítica de que os problemas do mal uso da água e suas consequências, assim como diversos problemas ambientais, é da responsabilidade de todos.

Nessa segunda etapa, professores e alunos perceberam que o processo de transformação - não desperdiçar água, uso e reuso da água, preservação dos mananciais, reflorestamento nos bairros e em locais próximos aos mananciais e outras ações -, é um processo que demanda tempo, entendimento e atitudes. Azevedo (1999, p. 72) afirma que "a escola é um espaço definido e significativo, onde as relações ensino e aprendizagem interpessoais e profissionais necessitam de mudanças.".

Durante o desenvolvimento do projeto foram realizadas reuniões com a equipe pedagógica, professores e alunos (toda a equipe do projeto). Nesse espaço é que foram elaboradas as ações, o questionário socioambiental que os alunos aplicaram aos moradores do entrono da escola e também aos seus vizinhos, visando identificar os principais problemas ambientais e sociais em relação aos recursos hídricos (uso e falta de água e outros).

Com os resultados do questionário, foi elaborado um planejamento de atividades de acordo com a realidade vivida na escola e na comunidade abordada, e, a proposta político pedagógica. Os professores ministraram aulas expositivas sobre sociedade e meio ambiente, manejo de recursos hídricos, descarte de lixo, reflorestamento, preservação e restauração ambiental, dentre outros assuntos relacionados.

Posteriormente professores e alunos realizaram saídas de campo objetivando integrar teoria e prática, despertando o interesse do aluno em relação ao meio em que vive. Foram visitadas as comunidades onde residem os alunos e professores, ressaltando que, alguns alunos moram nos arredores do distrito de Nascente, sendo eles filhos de agricultores (fazem uso de agrotóxicos, desmatam locais próximos aos mananciais e outras).

Nas oportunidades das saídas de campo, foram contextualizadas as teorias de sala de aula com as realidades vivenciadas pela comunidade onde alunos e professores moram e estudam / trabalham. Nessas atividades, foram coletadas amostras de água de uso doméstico, amostras de água da escola e dos mananciais que abastecem o distrito de Nascente. Foram anotados os problemas encontrados e questões acerca do meio ambiente. Posteriormente, a equipe do Projeto nas diversas discussões, elaboraram possíveis e simples soluções para a prática de ações sustentáveis da água e melhoria da qualidade de vida, lembrando a importância da arborização / reflorestamento nas comunidades, na escola e nas bordas dos mananciais.

Com apoio do governo municipal de Araripina e da Secretaria de Educação, o projeto conseguiu mudas de árvores suficientes para a execução de possíveis soluções. E ainda, a confecção de informes acerca do Projeto

"Qualidade de vida, ações sustentáveis", materiais como lixeiras para separação de lixo (para a reciclagem). 
Nota-se que a nessa experiência, aliando teoria e prática, o aluno aprendeu a fazer, fazendo, aprimorando sua formação na interpelação e na prática reflexiva. Os resultados do Projeto e todas as atividades realizadas na sua consecução foram apresentados para a comunidade escolar em um evento realizado nas dependências da escola (Figuras de 1 a 5).

Com as ações realizadas foi possível alertar professores alunos e toda a comunidade sobre doenças decorrentes de água poluída, mau uso da água (desperdício), reaproveitamento da água para atividades domésticas, importância de não realizar o desmatamento próximo aos mananciais, descarte de embalagens de agrotóxicos e lixo em locais apropriados e outras. O desenvolvimento do Projeto mostrou a importância dos recursos hídricos e a necessidade de preservação ambiental, constituindo numa ação para a sensibilização quanto ao uso dos recursos hídricos de Nascente, bem como as formas de degradação ambiental e possíveis soluções (ações sustentáveis) para diminui-la.

A terceira etapa foi a apresentação dos resultados do Projeto para a comunidade escolar, conforme está apresentado no item 4.4 dessa investigação.

\section{Papel da comunidade no Projeto}

A principal função do trabalho com o tema Meio Ambiente é contribuir para a formação de cidadãos conscientes, aptos para decidirem e atuarem na realidade socioambiental de um modo comprometido com a vida, com o bem-estar de cada um e da sociedade, local e global. Para isso é necessário que, mais do que informações e conceitos, a escola se proponha a trabalhar com atitudes, com formação de valores, com o ensino e a aprendizagem de habilidades. No contexto dessa investigação, a comunidade foi considerada: gestora pedagógica, professores e alunos do nono ano.

O papel da gestora/coordenadora pedagógica no Projeto "QUALIDADE DE VIDA E AÇÕES SUSTENTÁVEIS" foi contribuir com orientações didáticas, a fim de auxiliar o trabalho dos professores acerca do tema. Uma das orientações inclui uma revisão da prática pedagógica adotada (métodos/materiais utilizados, estratégias de abordagem, de mobilização, de envolvimento da escola e da comunidade, e outros). Outro papel da gestora é avaliar, diante dos resultados obtidos: a motivação geral, alcance dos objetivos, mudanças observadas nas pessoas e/ou nos ambientes, produtos obtidos, prazer no desenvolvimento das atividades e/ou na obtenção dos resultados, e outros. À coordenadora pedagógica cabe o papel de acompanhar todo o projeto.

Os professores do nono ano desde o início do projeto mostraram-se cientes das responsabilidades sócio-educativas a eles confiadas, existindo consenso da importância do tema transversal EA. Mostraram-se compromissados e interessados no projeto "QUALIDADE DE VIDA E AÇÕES SUSTENTÁVEIS" e na aplicação das atividades relacionadas ao mesmo. O principal papel do 
professor nesse projeto era o de promover interação entre atividades na escola e em estudos do meio, de modo que lhe fosse possível uma reflexão na prática. O papel do professor é ensinar (e aprender junto) aos alunos o trato com meio ambiente, em específico, no que se refere ao tema do projeto.

Para tanto, sabe-se da necessidade de ter conhecimento sobre seus conceitos e cuidados necessários à preservação e recuperação ambiental, para a tomada de consciência existencial, de como podem ser criados modos de ser e modos de vida de cada um. O papel do professor em sala de aula foi trabalhar os conceitos e suas considerações pautando-se nos PCNs, e, junto à coordenação pedagógica e aos alunos, elaborar ações que promovessem a EA (o projeto) inserida no PPP da escola.

Segundo Jonnaert e Borght (2002) cabe ao professor criar as condições necessárias para a aprendizagem do aluno, possibilitando para isto momentos, que correspondem às fases de preparação, realização e avaliação, sendo respectivamente: fase pré-ativa, interativa e pós-ativa.

Segundo eles o papel do professor é "organizar a dimensão interativa, contextualizando o saber a aprender”. Já o papel do aluno é “o de aprender” (p. 252).

Segundo Brasil (2002), cada professor, dentro da especificidade de sua área deve adequar o tratamento dos conteúdos para contemplar o Tema Meio Ambiente. Essa adequação pressupõe um compromisso com as relações interpessoais no âmbito da escola, para haver explicitação dos valores que se quer transmitir e coerência entre esses e os experimentados na vivência escolar, buscando desenvolver a capacidade de todos para intervir na realidade e transformá-la.

O papel do professor e o papel do aluno devem ser pensados como elementos fundamentais para organização escolar, pois é justamente na interação entre esses dois papéis que se dá o processo ensino aprendizagem.

\section{Reflexo do Projeto na comunidade escolar}

Particularmente no projeto "Qualidade de vida, ações sustentáveis", participaram gestores, professores e alunos, que, compartilharam pedagogicamente conhecimentos voltados para o correto manejo dos recursos hídricos (água) através de uma intervenção na prática pedagógica da escola.

Na apresentação dos principais resultados do Projeto "Qualidade de vida, ações sustentáveis", os alunos do $9^{\circ}$ ano levaram mudas para distribuir com os demais colegas da escola, falaram de todo o Projeto, de como o trabalharam; distribuíram, com a ajuda de colegas, os recipientes para o descarte correto de lixo pela escola; distribuíram um pequeno informe no qual explanam o Projeto, com as possíveis ações sustentáveis que toda a comunidade pode realizar em função de melhor qualidade de vida. 


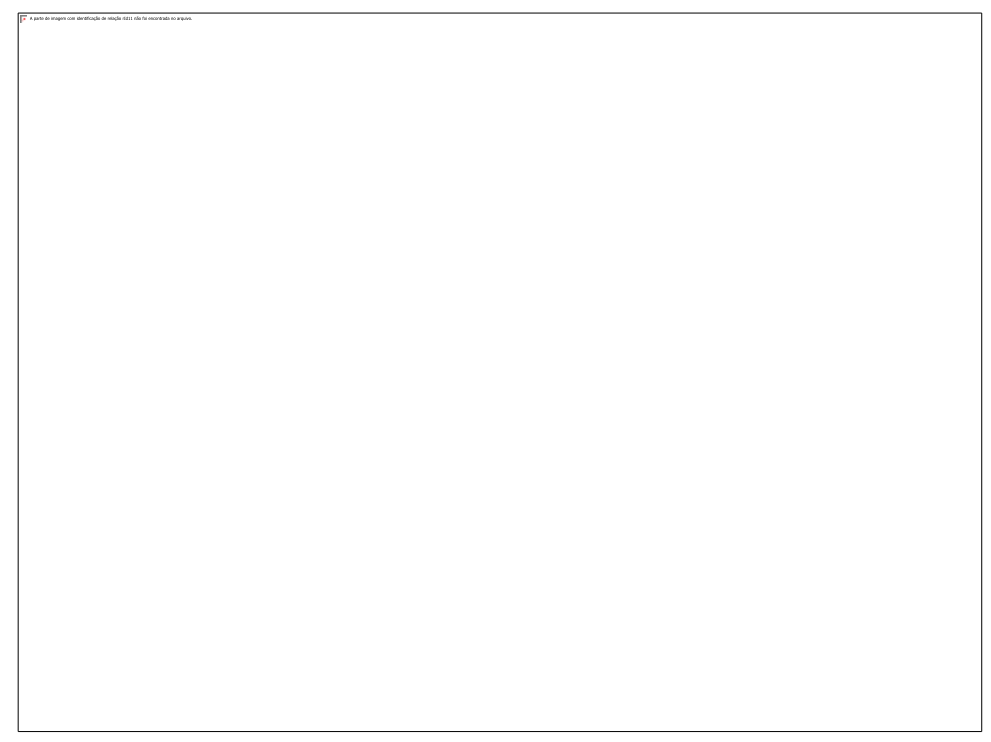

Figura 1- Apresentação dos resultados do Projeto II

Os alunos explanaram sobre a importância da conscientização de que a escola tem um papel relevante em relação à utilização e preservação dos recursos naturais, e que eles, os estudantes, são os principais agentes transformadores do meio ambiente e precisam ser instigados, sensibilizados ao uso consciente dos mesmos. Assim, serão pontes que levarão os conhecimentos adquiridos até a comunidade.

\begin{abstract}
A nossa escola enfrenta um grande problema de falta de água. Sendo semanalmente abastecida por carros pipas devido a um problema na encanação, que ainda não foi detectado pela Compesa (órgão responsável pelo tratamento e abastecimento de água em nossa comunidade). Isso compromete diretamente o trabalho da escola. No desenvolvimento do projeto, observamos também diariamente em nossa escola, a relação que jovens e crianças têm com o meio ambiente e os recursos naturais e verificamos que usam a água indiscriminadamente: desperdiçando a água dos bebedouros, banheiros, poluem o ambiente da sala de aula e entornos, entre outras atitudes antiéticas (ALUNOS DO $9^{\circ}$ ANO, agosto, 2015).
\end{abstract}

Os alunos falaram dos subprojetos inseridos do Projeto "Qualidade de vida, ações sustentáveis", como o projeto "Água: prevenir para preservar", desenvolvido de forma interdisciplinar, em busca de promover a construção de competências indispensáveis ao enfrentamento dos desafios gerados pela seca e a sensibilização da comunidade escolar para o uso responsável da água de suas casas e da escola, bem como sensibilizar-se da importância das Cacimbas para o abastecimento de água na comunidade, em caso de estiagem. 


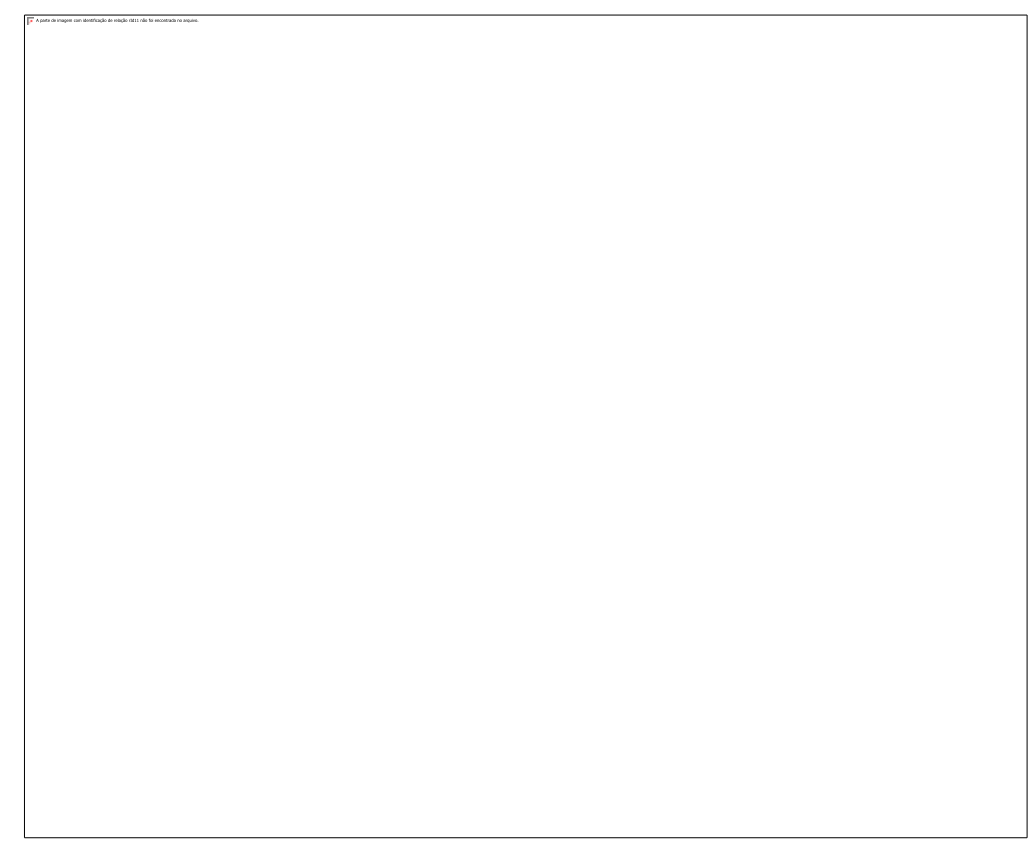

Figura 2- Explanação do Projeto com auxílio dos Professores

Os educadores atuam de forma interdisciplinar em seus componentes curriculares, com ações em favor da sustentabilidade: trabalhando com reciclagem, reaproveitamento de água, economia de energia elétrica, entre outras atividades de sensibilização na comunidade. O projeto foi desenvolvido com toda a escola, a partir dos alunos e professores do $9^{\circ}$ ano. A EA foi contemplada na escola no Projeto Político Pedagógico. Os professores se utilizam dos PCNs especificamente sobre o tema Educação Ambiental para elaborar seu plano de ensino, e também receberam curso de formação sobre EA.

Os professores observam em seus alunos algumas habilidades, pela prática dos projetos desenvolvidos na escola, tais como: identificam-se como parte integrante e responsável pela natureza; respeito às diversidades da natureza e sociais; analisar criticamente os fenômenos em prol da qualidade de vida; adoção de posturas na escola para o desenvolvimento sustentável; compreensão dos problemas ambientais de modo local; compreensão das relações causa / efeito que condicionam a preservação da vida; conhecimento de modo integrado as noções básicas relacionadas ao meio ambiente.

Todos os professores trabalham a EA em sua disciplina e se valem de estratégias e recursos como: textos informativos; exemplos e conteúdos inseridos na aula; trabalhos individuais e/ou em grupo; uso de multimídia em sala de aula (TV, vídeos e outros); projetos que aliam teoria e prática. Eles reconhecem que cotidianamente realizam atividades sobre EA. Os principais temas já trabalhados foram: conservação e preservação do meio ambiente; homem e meio ambiente; coleta seletiva e reciclagem; lixo, resíduos, descarte e destino do lixo; poluição: tipos, causas, consequências, atitudes de preservação e recuperação; alimentação saudável. 
Os professores sentem-se preparados para atuar como Educador Ambiental, e destacam que, alguns problemas ambientais detectados no município de Nascente, são: a degradação das cacimbas; o destino do lixo, e, a poluição pelo uso excessivo de agrotóxico. Os principais resultados alcançados com esse projeto foram: Redução em $70 \%$ o desperdício de água na escola; aumento para $90 \%$ o número de alunos que demonstram atitudes conscientes em relação ao cuidado e proteção ao ambiente escolar, entornos; redução de aproximadamente $30 \%$ os impactos provocados pelo mal uso da água na comunidade.

Os professores concordam que a avaliação do conhecimento e dos valores é feita por eles durante o desenvolvimento do projeto, de modo sistemático e contínuo, envolvendo os alunos e também os pais. A coordenadora pedagógica confirma o que dizem os professores, esclarecendo que, ao final do ano letivo de 2015, gestores e professores fizeram uma avaliação com os pais sobre todos os projetos desenvolvidos e viram que realmente os pais levantaram os projetos de Educação Ambiental como uma das prioridades, solicitando que projetos dessa natureza tivessem continuidade nas escolas.

Os pais, segundo se pode observar, reconhecem que em Nascente são muitos os problemas de ordem ambiental: o uso de agrotóxicos, o manejo dos recursos hídricos na região (uso indiscriminado e sem controle), descarte incorreto de lixo e outros. Nota-se que os projetos estão sensibilizando as famílias, ajudando a construir conhecimentos e instrumentalizando para a ação. Os pais destacaram que a escola está fazendo um trabalho que contribui na melhoria da qualidade de vida na escola e em casa, pois, conscientiza não só aos alunos e às suas famílias, fazendo com que todos se sintam responsáveis pelo ambiente onde moram.

Em função disso a EA é uma temática prioritária no Projeto Político Pedagógico da escola. Assim, o projeto "QUALIDADE DE VIDA E AÇÕES SUSTENTÁVEIS" vem atuando de forma efetiva na escola, nas famílias dos alunos (em casa) e nos bairros onde essas famílias moram, no sentido de contribuir para o melhor uso dos recursos hídricos, de forma preventiva por meio de práticas e processos com enfoque sustentável, seja de forma minimizadora ou corretiva, por meio de procedimentos que atenuem ou impeçam o avanço dos impactos negativos já instalados. Os subprojetos, assim como o principal, estão voltados para a geração de conhecimentos e práticas que promovam o uso sustentável dos recursos hídricos do distrito de Nascente.

As principais constatações / resultados, frutos do Projeto, foram: a comunidade escolar reconhece que por meio da educação ambiental é possível ensinar e aprender a como preservar e cultivar o meio ambiente. A comunidade se identifica com as seguintes afirmações: considera-se parte integrante da natureza e responsável por ela; respeita a diversidade da natureza; analisa criticamente os fenômenos naturais em favor da qualidade de vida; adota posturas em casa e na escola para o desenvolvimento sustentável; compreende os problemas ambientais de modo local. 
A comunidade utiliza água das cacimbas para o consumo diário, e, para preservá-las aprendeu que não deve interferir nas cacimbas, não se utilizar delas; não contaminar a água com mau uso e agrotóxicos; utilizar somente o necessário para o consumo e não desmatar seu entorno. Essa compreensão vem da constatação de alunos e professores de que a situação das cacimbas no início do projeto era que, elas encontram-se contaminadas pelo mau uso e atividades agropecuárias, além de estarem degradadas pelo desmatamento.

Seguindo os PCNs e os artigos da Lei Lei no 9.795/99 (LIPAI, LAYLARGUES e PEDRO, apud MELLO e TRAJBER, 2007), as disciplinas apreendidas na escola investigada trabalham visando à incorporação da dimensão ambiental de Nascente, em especial, dos alunos da Escola Estadual Anizio Rodrigues Coelho. Os alunos confirmam que por meio do Projeto "QUALIDADE DE VIDA E AÇÕES SUSTENTÁVEIS" realizaram diversas atividades pelas quais são hoje capazes de falar (por compreenderem) sobra uma diversidade de temas, como: chuva ácida; desenvolvimento sustentável; poluição do ar, água e solo; depredação; desperdício de energia. E, de modo especial, o manejo dos recursos hídricos de Nascente.

Entretanto, ao se voltarem aos problemas de ordem local, os alunos observaram que a questão das embalagens de agrotóxico ainda precisa melhorar, pois, são jogadas "no mato", apesar da conscientização de que devem ser devolvidas nas lojas especializadas, ou, até mesmo na EMBRAPA. Conforme Cruz (2005) a poluição e desequilíbrio por causa do uso de agrotóxicos não acontecem somente da aplicação, mas, também com o descarte de sua embalagem. Por estas ameaças, é que, segundo Castelo (2001) o agricultor precisa estar bem informado sobre os perigos, tipos de defensivos indicados para cada tipo de praga.

Assim, evidenciou-se que EA serve para conscientizar a todos da importância de conhecer e preservar o meio ambiente. É refletindo sobre a importância do meio ambiente para a nossa qualidade de vida, analisando as ofensas e agressões do homem à natureza, é que se conscientiza de que as suas atitudes podem fazer diferença. Um trabalho em rede, como o projeto desenvolvido por alunos e professores de nono ano da Escola Estadual Anízio Rodrigues Coelho trouxe resultados positivos além dos esperados e a degradação ambiental, bem como o melhor uso dos recursos hídricos se reverterá aos poucos mediante a participação de toda a sociedade de Nascente como um todo, não somente nas suas ações diárias, mas também na tentativa da conscientização sendo todos multiplicadores de novo estilo de vida que se deve e é possível adotar. 


\section{Conclusões}

O principal objetivo foi saber como acontece a educação ambiental na Escola Estadual Anízio Rodrigues Coelho a partir do projeto "Qualidade de vida e ações sustentáveis". Para tanto se realizou uma pesquisa de enfoque qualitativo, uma pesquisa participante, da qual se contou com a participação de professores e alunos do $9^{\circ}$ ano da escola investigada, além da coordenadora pedagógica.

Com relação às propostas do Projeto "QUALIDADE DE VIDA E AÇÕES SUSTENTÁVEIS”? Constatou-se que o principal objetivo foi articular a comunidade escolar para o desenvolvimento de práticas sustentáveis, em benefício do bem próprio e coletivo. Para tanto, alunos e professores do $9^{\circ}$ ano, orientados pela coordenadora pedagógica diagnosticaram a real situação do uso da água na escola e em suas residências. Outras metas foram estabelecidas no intuito de conscientizar a todos da importância do uso sustentável da água nesses ambientes. Dentre as principais ações sustentáveis, notou-se: a articulação com empresas parceiras para aquisição de um poço artesiano; arborização do entorno da escola; construção de canteiros sustentáveis para o cultivo de hortaliça; aquisição de mudas frutíferas e outras. A avaliação do projeto, evidencia mudança de comportamento sócio ambiental de toda a comunidade escolar e local, nas vivências de práticas e ações que consolidem o propósito de Sustentabilidade no ambiente escolar, utilizando de forma inteligente os recursos da natureza, de modo especial, a água.

Sobre como se desenvolveu o projeto "QUALIDADE DE VIDA E AÇÕES SUSTENTÁVEIS”, constatou-se que o mesmo aconteceu em três etapas: 1. Formação do grupo principal; diagnóstico dos problemas acerca do mal uso dos recursos hídricos na escola e em residências; busca de referencial teórico sobre a temática. 2. Realização de ações pedagógicas interdisciplinares do projeto na escola, nos bairros e residências dos alunos e professores visando uma transformação no comportamento da comunidade escolar capaz de promover a melhoria da qualidade de vida pelo uso sustentável dos recursos hídricos. Foram realizadas aulas expositivas sobre diversos temas que facilitam a compreensão da sustentabilidade no uso de recursos hídricos. E também, saídas de campo objetivando integrar teoria e prática, onde foram coletadas amostras de água de uso doméstico, amostras de água da escola e dos mananciais que abastecem o distrito de Nascente. A partir dos problemas levantados, foram elaboradas possíveis e simples soluções para a prática de ações sustentáveis da água e melhoria da qualidade de vida da comunidade escolar. 3. Apresentação dos resultados do Projeto para a comunidade escolar, por meio de registros fotográficos, análise das contas de água, divulgação (resumo) do projeto na escola, distribuição de mudas e materiais para a coleta seletiva de lixo. Objetivo alcançado.

Quanto ao papel da comunidade escolar no desenvolvimento do projeto, constatou-se que o principal papel da equipe que desenvolveu o projeto era o de contribuir para a formação de cidadãos conscientes, aptos para decidirem e atuarem na realidade em que vivem. Para tanto, a gestora pedagógica 
contribuiu com orientações didáticas, a fim de auxiliar o trabalho dos professores, no que se refere a uma revisão da prática pedagógica adotada. Além disso, acompanhar e avaliar o desenvolvimento de todo o projeto, do diagnóstico aos resultados. Aos professores coube cumprir com suas responsabilidades sócio-educativas, promovendo interação entre atividades na escola e em estudos do meio e a reflexão na prática. O papel do professor e o papel do aluno, nessa investigação foram pensados como elementos de interação entre teoria e prática, ou seja, aprenderem e ensinarem juntos. Objetivo alcançado.

Sobre o reflexo do projeto na comunidade da Escola Estadual Anízio Rodrigues Coelho, observou-se: compartilhamento de conhecimentos interdisciplinares entre gestora pedagógica, professores e alunos sobre o correto manejo dos recursos hídricos (água) através de uma intervenção na prática pedagógica da escola; distribuição de materiais e produtos que auxiliam na compreensão do tema abordado, na prática de possíveis ações para evitar o desperdício de água e outras providências para melhorar a qualidade vida; conscientização da comunidade escolar sobre o uso consciente dos recursos hídricos; práticas de ações sustentáveis (horta, reuso de água, descarte correto de lixo e embalagens de agrotóxicos, reorganização ambiental no entorno da escola e dos mananciais pela arborização, revisão nos vazamentos, etc.). Nos resultados apresentados do Projeto, confirmou-se: dedução em $70 \%$ o desperdício de água na escola; aumento para $90 \%$ o número de alunos que demonstram atitudes conscientes em relação ao cuidado e proteção ao ambiente escolar, entornos; redução de aproximadamente $30 \%$ os impactos provocados pelo mau uso da água na comunidade.

$\mathrm{O}$ projeto parece ter produzido resultados que mostram a mudança de comportamento da comunidade escolar por meio da prática de ações sustentáveis, como reorganização ambiental (hortas, praças, áreas próximas aos mananciais); uso e reuso da água na escola e nas residências.

A EA praticada na escola investigada demostra potencial em proporcionar relações concretas entre os conteúdos e a realidade da comunidade escolar, valorizando a prática pedagógica no investimento de uma prática reflexiva e de trabalho coletivo na solução dos problemas ambientais sob a perspectiva sociocultural e educativa da formação do cidadão no contexto escolar.

\section{Referências}

ABREU, Carlos. A sustentabilidade nas escolas. Atitudes sustentáveis. Publicado em 05 jul. 2010. Disponível em: <http://www.atitudessustentaveis.com.br/conscientizacao/ asustentabilidade-nas-escolas/>. Acesso em: 09 abr. 2011.

AMBICENTER. Portal de Informação e Legislação Ambiental. Arquivos. Educação Ambiental: A floresta e a água. Publicado pela AFUBRA - Associação dos Fumicultores do Brasil, sem data. Disponível em: <http://www.Ambicenter.com.br/ea01052200.htm〉. Acesso em: 15 fev. 2011. 
AZEVEDO, G. C. de. Uso de jornais e revistas na perscpetiva da representação social de meio ambiente em sala de uala. In: REIGOTA, Marcos. Verde cotidiano: $\mathbf{O}$ meio ambiente em discussão. Rio de Janeiro - RJ: DP\&A, 1999, pp. 72.

BRASIL. Constituição. Emenda Constitucional. Brasil. 3ª Revisão Constitucional, Brasil, 1998.

BRASIL, Ministério da Educação. Políticas de melhoria da qualidade da educação: um balanço institucional. Secretaria da Educação Fundamental. Brasília - DF: MEC/SEF, 2002.

BRASIL. Secretaria de Educação Fundamental. Parâmetros Curriculares Nacionais: Meio Ambiente e Saúde. Brasília, 1997.

. Ministério do Meio Ambiente. Política Nacional de Educação Ambiental. Lei $\mathbf{n}^{\mathbf{0}}$ 9.795, de 27/04/1999. Brasil: MEC, 1999.

CAPRA, F. Falando a linguagem da natureza: princípios da sustentabilidade. In: STONE, M. K.; BARLOW, Z. (orgs). Alfabetização Ecológica: a educação das crianças para um mundo sustentável. Tradução de Carmen Fischer. São Paulo: Cultrix, 2006.

Alfabetização Ecológica: O Desafio para a Educação do Século 21. In: TRIGUEIRO, A. (coord.). Meio Ambiente no Século 21: 21 especialistas falam da questão ambiental nas suas áreas de conhecimento. Rio de Janeiro: Sextante, 2003.

CASTElO, Celina Maria Montenegro. Construindo a cidadania no Ceará - Educação Agrícola. Fortaleza: Secretaria de Educação do Ceará, 2001.

CRUZ, Daniel. Ciências \& Educação Ambiental. 3. ed. São Paulo - SP: Ática, 2005.

DIAS, Genebaldo F. Educação Ambiental: princípios e práticas. São Paulo - SP: Gaia, 2000.

FARIA, Caroline. Pagamento por Serviços Ambientais. InfoEscola, 2009. Disponível em: $<\mathrm{http} / / / \mathrm{www}$.infoescola.com/ecologia/pagamento-porservicos-ambientais-psa/>. Acesso em: $18 \mathrm{dez}$. 2010.

FELIZARDO, Alexandra; ROBERTO, Helena; DIREITINHO, João; PESTANA, João. Degradação Ambiental. $8^{\circ}$ Seminário Internacional Sobre Áreas Contaminadas. Realizado de 22 a 23 de outubro de 2009 em São Paulo - SP. Disponível em: <http://pt.scribd.com/doc/13586584/Degradacao-Ambiental:. Acesso em: 07 nov. 2010.

HENRIQUES, Ricardo; TRAJBER, Rachel; MELLO, Soraia; LIPAI, Eneida M.; CHAMUSCA, Adelaide. Educação Ambiental: aprendizes de sustentabilidade. Caderno SECAD 1. Brasília - DF: Secretaria de Educação Continuada, Alfabetização e Diversidade (Secad/MEC), 2007.

JONNAERT, P; BORGHT, C. V. Criar condições para aprender: o modelo sócio construtivista na formação de professores. Porto Alegre - RS: Artmed, 2002.

MACHADO, N. J. Educação: projetos e valores. São Paulo - Sp: Escrituras Editora, 2000. 
MELLO, Soraia Silva de; TRAJBER, Raquel. (coord.). Vamos cuidar do Brasil: conceitos e práticas em educação ambiental na escola. Ministério da Educação. Coordenação Geral de Educação Ambiental. Ministério do Meio Ambiente. Departamento de Educação Ambiental. Brasília: UNESCO, 2007.

MINAYO Maria Cecília de Souza. O desafio do conhecimento: pesquisa qualitativa em saúde. Rio de Janeiro: Abrasco, 2007.

MPF. Ministério Público Federal. Resíduos. Programa de Gestão Ambiental. S/d. Disponível em: <http://pga.pgr.mpf.gov.br/pga/residuos>. Acesso em: 16 ago. 2011.

NADAL, Paula. Como fazer uma escola sustentável. Gestão Escolar, mai. 2010.

NADAL, Paula; LOPES, Noêmia. Estruturas e ações para uma escola sustentável. Nova Escola, mai. 2010.

OLIVA, J. M.; MATOS, J.; BUENO, E.; BONAT, M.; DOMÍNGUEZ, J.; VÁSQUEZ, A. Y ACEVEDO, J. A. Las exposiciones científicas escolares y su contribuición en el ámbito afectivo de los alimnos participantes. Invesutigación Didáctica. Enseñanza de las Ciencias. 2004. pp. 425-439.

PASQUALI, Ísis Samara Ruchel; CUNHA, Jader Tomazetti da; MASSING, Jacsson; ABICHT, Alexandre de Melo. Educação Ambiental: Educação Ambiental no Ensino Médio de Biologia. III SEGeT - Simpósio de Excelência em Gestão e Tecnologia, 2006.

PELICIONI, Maria Cecília Focesi. Educação em saúde e educação ambiental estratégias de construção da escola promotora da saúde. LivreDocência. Universidade de São Paulo, Faculdade de Saúde Pública, 2000.

PINTO, Mario da Silva; ABREU, Álvaro de Paiva. Coleta e disposição do lixo no Brasil. Rio de Janeiro - RJ: CONSULTEC/FGV, 2003.

RIZOMAS. Recursos didáticos. Aulas práticas. 2008. Disponível em: <http://www.rizomas.net/utilidades-para-professores/aulas-praticas-deciencias.html>. Acesso em: 30 jun. 2011.

RODRIGUES, Ana Paula da Mota; RODRIGUES, Milena Goulart de Souza. A educação ambiental e os Parâmetros Curriculares Nacionais: um olhar sobre a transversalidade da questão. Projeto Final de Curso. Programa de Formação Profissional em Ciências Ambientais. Rio de Janeiro: Universidade Federal do Rio de Janeiro, 2001.

VASCONCELLOS, H. S. R. A pesquisa-ação em projetos de Educação Ambiental. In: PEDRINI, A. G.; SILVEIRA, D. L.; DE PAULA, J. C.; VASCONCELlOS, H. S. R.; CASTRO, R. S. Educação ambiental: reflexões e práticas contemporâneas. Petrópolis: Vozes, 1997.

\section{Como citar este artigo (Formato ABNT):}

CORDEIRO, Eva L. de M. e VIDEIRA, Márcia Cristina M. C. A Educação Ambiental na Escola Estadual Anízio Rodrigues Coelho, à partir do Projeto "Qualidade de Vida e Ações Sustentáveis". Id on Line Rev.Mult. Psic., 2018, vol.12, n.40, p.527-547. ISSN: 1981-1179.

Recebido: $26 / 04 / 2018$

Aceito: $10 / 05 / 2018$ 